\title{
Experimental Study on Developing Flexible Tubes with Turbulent Drag Reduction Effects
}

\author{
Shupeng Cai, Gao Peng, Binwen Luo \\ School of Mechanical Engineering, Hunan University of Technology, Zhuzhou 412007, China
}

Keywords: Flexible tubes, Sleeve-structured tube, Turbulent drag reduction.

\begin{abstract}
In order to probe into developing technology for pipe fluid transportation with drag reducing effects by using a flexible tube, an experimental study was performed on the effects of turbulent drag reduction by using sleeve-structured flexible tubes in the operating conditions that there are water and air with pressure to be almost equivalent to the pressure on inner wall surface, on external wall surface of the flexible tubes. The results are found as follow: the thinner the flexible tubes, the bigger the decrease rate of the friction coefficient is; compared the drag reduction rates in operating condition of pressure balancing air with those in operating condition of pressure balancing water, the drag reduction rates for former are bigger, at $\mathrm{Re}=17500$, the drag reduction rates of the flexible tubes with thickness of $2 \mathrm{~mm}, 3 \mathrm{~mm}$ and $4 \mathrm{~mm}$, are about $12 \%, 10 \%$, $9 \%$. This would offer a new view for developing technology of efficient fluid transportation.
\end{abstract}

\section{Introduction}

It's very important to develop energy-saving and friction drag reduction technologies for resolving the contradiction among global sustainable development, energy's drying up and increasing energy consumption with population's growth and industry's rapid development.

The fluid transportation via industrial pipeline is done essentially in turbulent flow patterns, so the turbulent friction drag reduction is an inevitable requirement for transporting fluid effectively. The turbulent friction drag reduction focus on changing the turbulent coherent structure in the boundary layer on solid wall to reduce the internal energy dissipation. The representative methods for reducing friction drag are as follow: adding polymer or surfactant into fluid based on the Toms' effects, riblet, large eddy brake up device and compliant wall. With regard to riblet, since reported by Walsh ${ }^{[1]}$ first, many investigations were carried out and the mechanism was clarified by the study which focused on the coherent structure of turbulence in boundary layer on riblet. With respect to compliant wall, Since Kramer ${ }^{[2]}$ had reported about the friction drag effect in boundary layer on compliant wall, a number of investigations ${ }^{[3,4]}$ have been performed. For the purpose of fluid transportation, a compliant wall may be called a flexible tube. It is unclear whether a flexible tube can reduce friction drag. The data have not yet clearly confirmed the effectiveness of a flexible tube. Only one method ${ }^{[5]}$ for evaluating the friction drag reduction has been utilized so far, that is, by measuring the fluctuating velocity characteristics on the center axis of a flexible tube. To our knowledge, the research which is on the friction drag reduction using flexible tubes is rare except the literature ${ }^{[6,7]}$. In that report, Fukuhara have studied the friction drag reduction by a flexible tube, evaluating the friction coefficient after the reduction due to the variation of flow sectional area is subtracted from the friction coefficient for a rigid tube, with the hypothetical model ${ }^{[7]}$. The drag reduction rate of the flexible tube whose inner diameter and the thickness are $10 \mathrm{~mm}$ and $1.5 \mathrm{~mm}$ is $22 \%$ at $\mathrm{Re}=3.0 \times 10^{4}$. The tendency of the drag reduction for a flexible tube is believable, but the magnitude of the drag reduction is dubitable, because of directly using inner diameter of a flexible tube shown by the material manufacturer and inaccurately evaluating the drag reduction due to the variation of flow sectional area.

In the present research, we experimentally examined the friction drag reduction using a flexible tube for developing a flexible tube with friction drag less than that of a rigid tube, from a fluid dynamic perspective. The coefficient of friction of a flexible tube was measured in the fully developed turbulent flow region and was compared with that of a rigid tube. Tube diameter changes 
as pressure on inner wall surface changes with flow rate, though it can not be accurately measured. This is the difficult point of researching how to accurately and dependently evaluate the effect of friction drag reducing bye using flexible tubes. We firstly used the tube diameter in the laminar region to calculate the friction coefficient of a flexible tube in the atmosphere pressure operating condition, and confirmed the effects of the friction drag reduction, then used the sleeve-structure tubes whose outer wall is connected to inner wall of a flexible tuber to keep tube diameter at the constant size, the coefficient of friction of the flexible tube was measured and compared with that of a rigid tube in operating conditions full of water and air on outer wall surface of a flexible tube, the reduction of friction drag obtained in this case can be considered to be due to the effects of the flexible tube, because of keeping the tube diameter constant. The following $\mathrm{A}, \mathrm{B}$ and $\mathrm{C}$ denote the three experimental operating condition set on the outer wall surface of a flexible tube.

\section{Apparatus and methods of the experiment}

\subsection{Apparatus of the experiment}

The experimental apparatus is shown in figure 1.

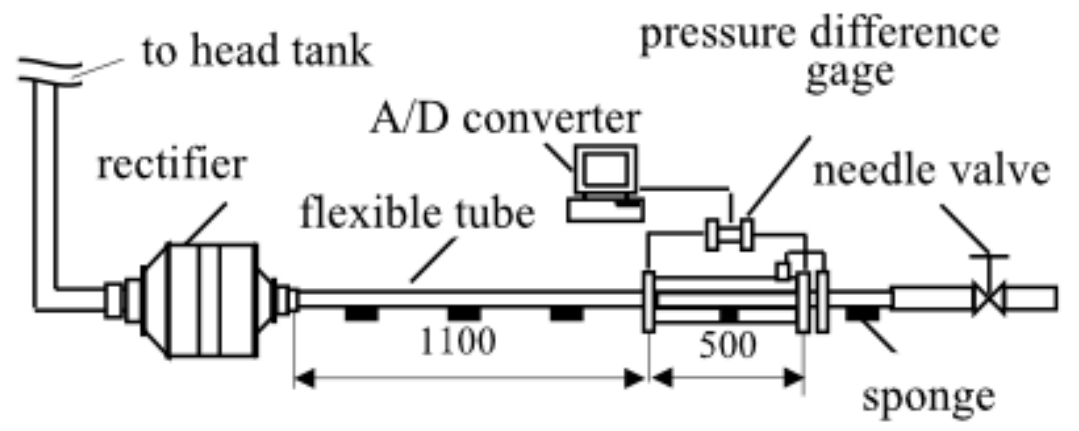

Fig 1 Schematic of experimental apparatus

The water as working fluid flows from the head tank which keep a constant water head through the rectifier where it is regulated and accelerated into the test section with sleeve-structure for measuring pressure loss, then flows through the needle valve, and into the atmosphere.

\subsection{Materials for the experiment}

In the present research, three flexible latex circular tubes of different thicknesses constructed of the same material were used, the inner diameter shown by the material maker for all tubes is $12 \mathrm{~mm}$, Young's modulus, Density, Poisons ratio and Damping Coefficient for latex are $3.5 \mathrm{Mp}_{\mathrm{a}}, 1.15 \times 10^{3} \mathrm{~kg}$ $/ \mathrm{m}^{3}, 0.45$, and 0.05 , respectively.

\subsection{Methods for the experiment}

To prove the reliability of the experiment apparatus, we used the rigid transparent fiberglass pipe whose Inner Diameter and wall thickness respectively are $13 \mathrm{~mm}$ and $3 \mathrm{~mm}$ as the testing pipe tube for a preparative experiment before the formal experiment. The result of the experiment indicates that the friction coefficient of the rigid tube in turbulent region is basically conformed to the Blasius's empiric equation, which confirm the availability of the experimental apparatus by the testing method.

After the effects of friction drag reduction of the flexible tubes in fully developed turbulent region had been proved, by using the tube diameter in laminar region in operating condition $\mathrm{A}$, the rates of drag reduction using the flexible tubes were evaluated by comparing it with the friction coefficient of the rigid tube, by the sleeve-structured flexible tubes in operating condition $\mathrm{B}$ and $\mathrm{C}$, The flow rate was adjusted by the needle valve downstream, a industrial injector was used to inject air on the outer wall surface of the flexible tubes.

According to the magnitude of pressure losses, the four differential pressure sensors of $5 \mathrm{mmAq}$, $100 \mathrm{mmAq}$ and $200 \mathrm{mmAq}$ were used respectively to measure the pressure losses in test section of the flexible tubes by higher precision. The flow rate is measured with the weighting method. 


\section{Analysis of the experimental results}

\subsection{Count of the tube diameter}

The Equation (1) can be used to calculate tube diameter in the condition in which coefficient of friction of a pipe flow in fully developed laminar region is consistent with Hagen-Poiseuille Equation.

$$
d=\left(\frac{128 \rho L v Q}{\Delta p \pi}\right)^{0.25}
$$

Where $d$ is the tube diameter at some flow rate in the laminar region(m), $\rho$ is the density of water $\left(\mathrm{kg} / \mathrm{m}^{3}\right) ; L$ is the length of the test section $(\mathrm{m}) ; \quad v$ is the kinematic viscosity of water $\left(\mathrm{m}^{2} / \mathrm{s}\right) ; \quad Q$ is the flow rate $\left(\mathrm{m}^{3} / \mathrm{s}\right) ; \Delta \mathrm{p}$ is the pressure difference $\left(\mathrm{N} / \mathrm{m}^{2}\right)$.

A referenced tube diameter was determined by using least squares procedure to the data array of tube diameter in laminar region which is calculated by equation(1), the friction coefficient and Reynolds numbers were calculated by using this referenced tube diameter. Evidently, the referenced diameter in operating condition $\mathrm{A}$ is lager than the true diameter of the flexible tubes in turbulent region, in three operating conditions $\mathrm{A}, \mathrm{B}$ and $\mathrm{C}$, the referenced diameters for the flexible tubes in laminar region are shown in Table 1.

Table 1 The referenced diameter for the flexible tubes

\begin{tabular}{cccc}
\hline operating condition & $2 \mathrm{~mm}$ thickness & 3mm thickness & 4mm thickness \\
\hline A & $11.62 \mathrm{~mm}$ & $11.54 \mathrm{~mm}$ & $11.80 \mathrm{~mm}$ \\
B & $11.68 \mathrm{~mm}$ & $11.58 \mathrm{~mm}$ & $11.84 \mathrm{~mm}$ \\
C & $11.63 \mathrm{~mm}$ & $11.56 \mathrm{~mm}$ & $11.82 \mathrm{~mm}$ \\
\hline
\end{tabular}

\subsection{Friction coefficient of the flexible tubes}

The influence of the change of the tube diameters on the friction coefficient can be deduced by the definition equation of pressure loss for a circular pipe flow:

$$
\lambda=\frac{\pi^{2} \Delta p}{8 \rho L Q^{2}} d^{5}
$$

From equation (2), how much influence of the error of the tube diameter on drag reduction can be seen. This is the reason why the tube diameter shown by the material manufacturer was not used in the present study.

The friction coefficients versus the Reynolds numbers in operating condition A.B and C are shown in figure 2, 3 and 4 respectively.

From figure 2, in operating condition A, even if the friction coefficient of flexible tubes obtained by using the referenced diameter which is larger than the true diameter in turbulent region it is smaller than that for the rigid tube, which do confirme the effect of friction drag reduction due to the effects of the flexible tubes and that is in accord with the report of reference ${ }^{[7]}$. As the results of figure 3 and 4 show, the friction coefficient in operating condition $\mathrm{B}$ and $\mathrm{C}$ is obvious sly lower than that of the rigid tube, as deduced from figure 2 .

\subsection{Friction drag reduction rate for the flexible tubes}

Figure 6,7and 8 indicate, the rates of the friction drag reduction of flexible tubes compared with the rigid tube whose friction coefficient conforms to Blasius equation, in operating condition of experiment $\mathrm{A}, \mathrm{B}$ and $\mathrm{C}$, the friction drag reduction rate are expressed by equation (3):

$\mathrm{DR}=\left(0.3164 \mathrm{Re}^{-0.25}-\lambda\right) / 0.3164 \mathrm{Re}^{-0.25}$

The results in figure 5, 6 and 7 show:

(1) In the operating condition $B$, the rate of the friction drag reduction of the flexible tube of $2 \mathrm{~mm}$ is the biggest, and that of the $4 \mathrm{~mm}$ tube is the smallest, the rates increase with the decrease of the thickness of the wall, and increases with Re increasing in the range of Re measured, but the gradient is getting smaller and smaller, from equation(2) it can be understood that the friction drag reduction 
rates of $2 \mathrm{~mm}$ and $3 \mathrm{~mm}$ tubes are bigger than those in operating condition $\mathrm{A}$, which is due to the effect of the sleeve-structured tubes of successfully controlling variation of the flexible tubes diameter. But the drag reduction rate of the $4 \mathrm{~mm}$ flexible tube is lower than that in operating condition $\mathrm{A}$, because the diameter of this tube basically doesn't change with the operating conditions and the flow rates, and in operating condition B, the vibration degree of the flexible tube which can increase the effect of friction drag reduction is suppressed by water full of on the outer wall surface of the flexible tube.

(2) In the operating condition $C$, the drag reduction rate of the flexible tubes is the same in tendency as in operating condition $\mathrm{B}$, but it is bigger than the latter. At $\mathrm{Re} \approx 17500$, the friction drag reduction rate of the $2 \mathrm{~mm} .3 \mathrm{~mm}$ and $4 \mathrm{~mm}$ flexible tubes is about $12 \%, 10 \%$ and $9 \%$, which shows that there are weaker damping effects for the effective vibration of the flexible tube which can weaken friction drag in operating condition $\mathrm{C}$ than in operating condition $\mathrm{B}$. From figure 8 , the influence in operating condition $\mathrm{C}$ on the drag reduction of the flexible tubes can be made negligible.

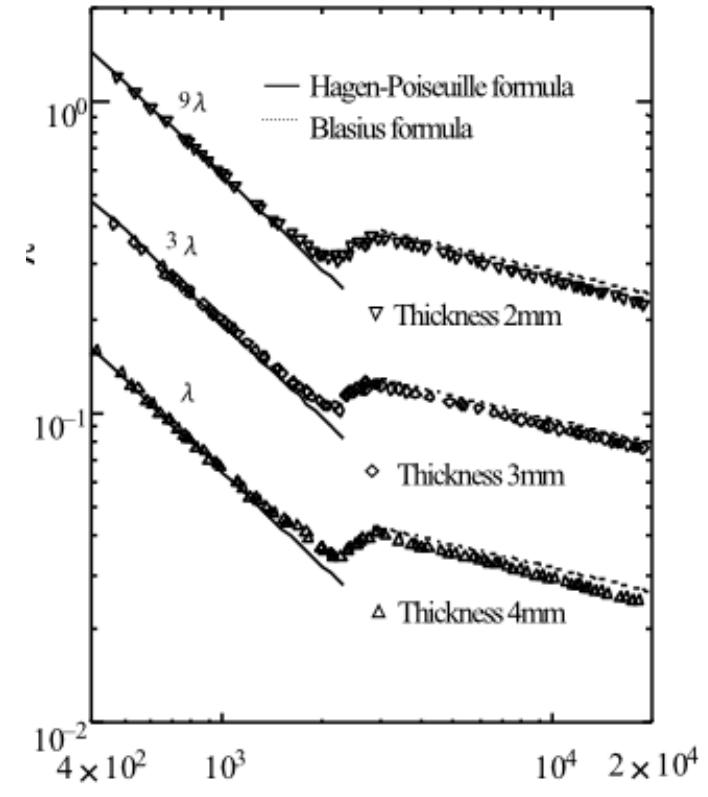

Fig 2 Friction coefficients of flexible tubes versus Re for operating condition A

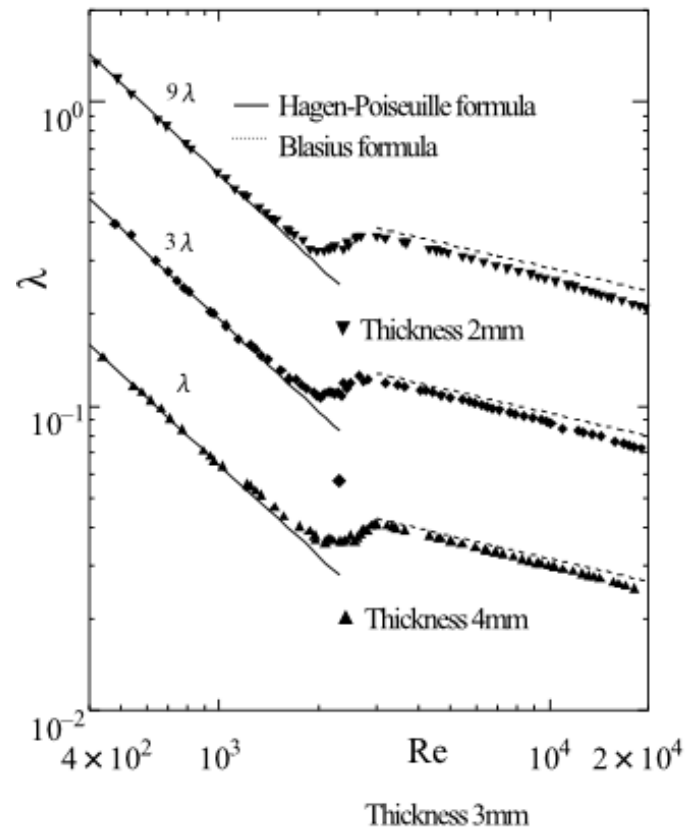

Fig 3 Friction coefficients of flexible tubes versus Re for operating condition $\mathrm{B}$

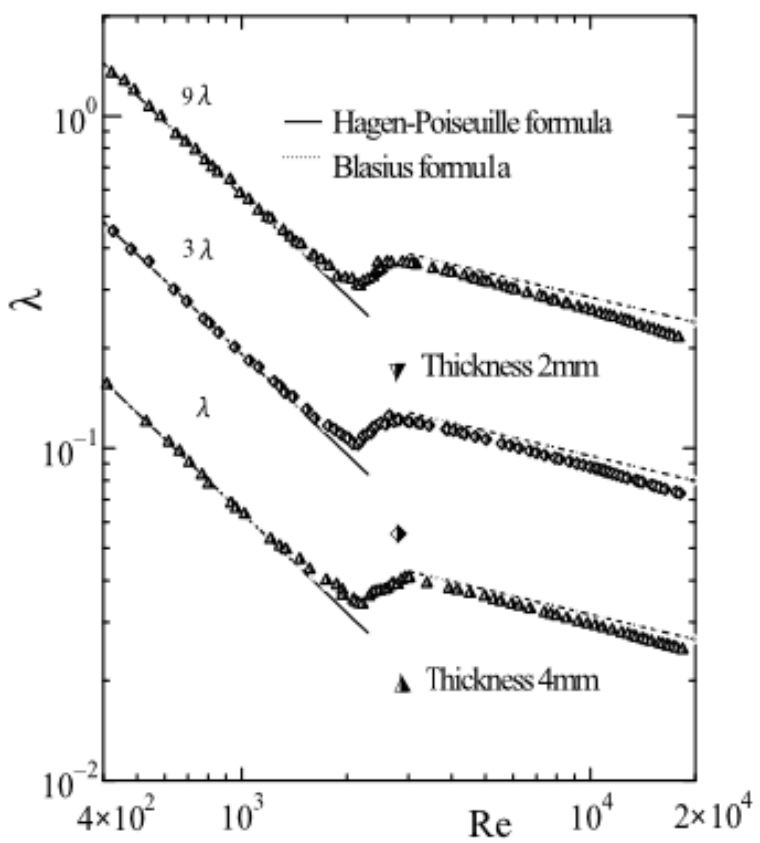

Fig 4 Friction coefficients of flexible tubes versus Re for operating condition C 


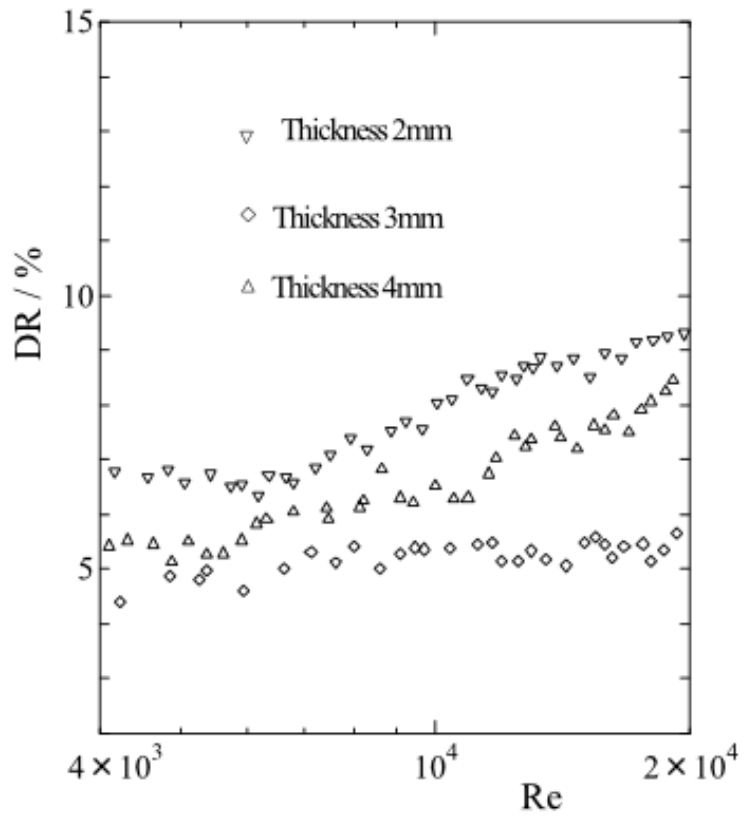

Fig 5 Drag reduction rates of flexible tubes versus Re for operating condition A

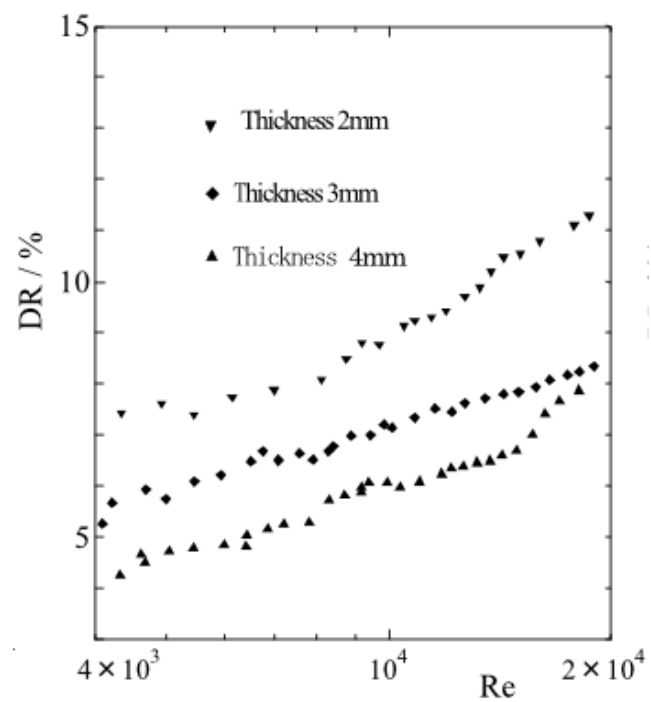

Fig 6 Drag reduction rates of flexible tubes versus Re for operating condition B

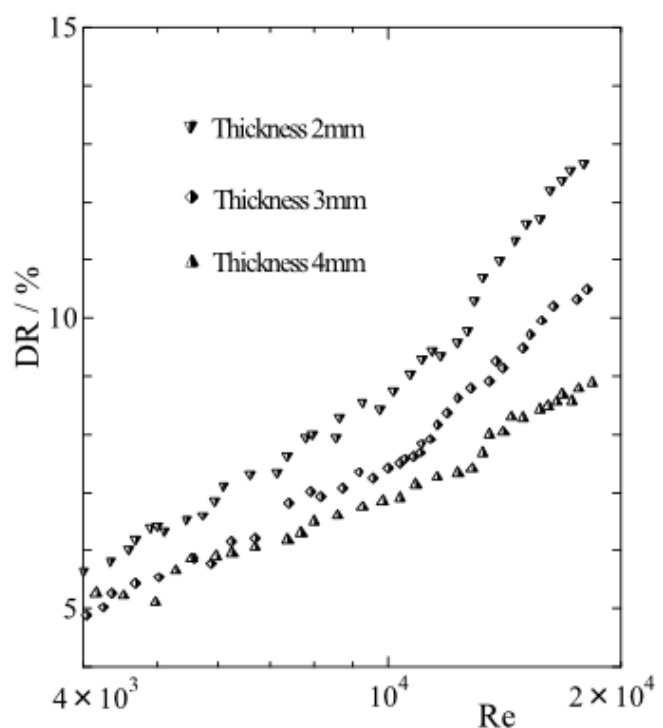

Fig 7 Drag reduction rates of flexible tubes versus Re for operating condition C 


\section{Conclusion}

We obtained the following conclusion from the present research:

The flexible tubes really has the effect of friction drag reduction in turbulent region, and the drag reduction rate increases with the decreasing of wall thickness of the flexible tube, and in the range of Re measured, the drag reduction rates of the flexible tubes increase with the Re increasing, but the gradient is getting smaller and smaller, at $\operatorname{Re} \approx 17500$, the friction drag reduction rate of $2 \mathrm{~mm}, 3 \mathrm{~mm}$ and $4 \mathrm{~mm}$ flexible tubes are about $12 \%, 10 \%$ and $9 \%$, in operating condition C; filling pressure balancing air to the outer of the tube has smaller influence on friction drag reduction than filling pressure balancing water to the outer of the flexible tubes.

\section{Acknowledgements}

This work is being supported by the National Natural Science Foundation of China through grant No. 51476051.

\section{Reference}

[1].Wash, M.J., Turbulent Boundary Layer Drag Reduction Using Riblet, AIAA Paper, 820169(1982)

[2]. Kramer M O, Boundary layer stabilization by distributed damping [J].Am.Soc.Nav.Engrs, 1960, 6(72): 25-33.

[3].Arakawa, M., Critical Reynolds Numbers for the Flow in Flexible Tubes [J]. Transaction. Japaneses .Society Biorheology, 1982,21 (5) :226-232.

[4].T Lee M. Fisher and W. H. Schwarz, Investigation of stable interaction of a passive compliant surface with a turbulent boundary layer[J]. Fluid Mech. 1993, 257: 373-401.

[5].Fukuhara, T, Experimental Study on Drag Reduction Using Flexible tubes [J]. JSM series B, 1998, 40(1): 77-85

[6].Nakao S, A, Suzuki M, Numerical Study of Drag Reduction By Compliant Walls [J]. Trans. Jpn. Soc. Aero. Space. Sci., 1985,(27)78: 195-201.

[7].Bushnell D M, Effect of compliant wall motion on turbulent boundary layers [J], Phys. Fluids, 1977,(20)10: 31-47. 